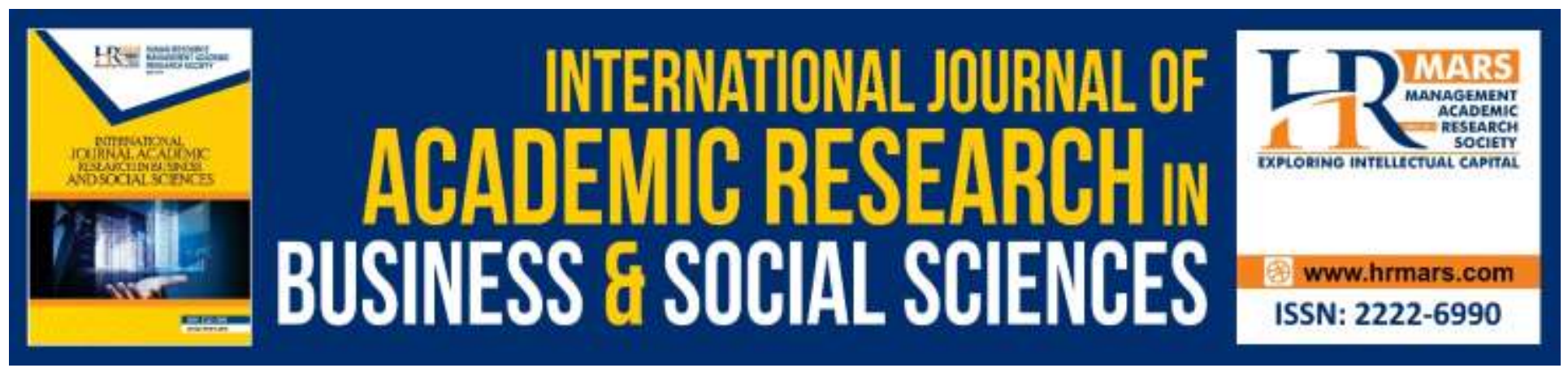

\title{
Multidimensional Psychometric Evaluation of Secondary School Student Aggression and Its Proposed Solution Based on Integrated Social Pedagogy
}

\author{
Abd. Rahim Mohd. Shariff, Norliza Abdul Majid, Hazuan Mohd Hizan, \\ Ali Md Nadzalan \& Nik Mohd. Zaki
}

To Link this Article: http://dx.doi.org/10.6007/IJARBSS/v9-i2/5550

DOI: $10.6007 /$ IJARBSS/v9-i2/5550

Received: 14 Jan 2019, Revised: 26 Feb 2019, Accepted: 12 March 2019

Published Online: 17 March 2019

In-Text Citation: (Shariff, Majid, Hizan, Nadzalan, \& Zaki, 2019)

To Cite this Article: Shariff, A. R. M., Majid, N. A., Hizan, H. M., Nadzalan, A. M., \& Zaki, N. M. (2019).

Multidimensional Psychometric Evaluation of Secondary School Student Aggression and Its Proposed Solution Based on Integrated Social Pedagogy. International Journal of Academic Research in Accounting, Finance and Management Sciences, 9(2), 353-362.

Copyright: (C) 2019 The Author(s)

Published by Human Resource Management Academic Research Society (www.hrmars.com)

This article is published under the Creative Commons Attribution (CC BY 4.0) license. Anyone may reproduce, distribute, translate and create derivative works of this article (for both commercial and non-commercial purposes), subject to full attribution to the original publication and authors. The full terms of this license may be seen

at: http://creativecommons.org/licences/by/4.0/legalcode

$$
\text { Vol. 9, No. 2, 2019, Pg. } 353-362
$$

Full Terms \& Conditions of access and use can be found at http://hrmars.com/index.php/pages/detail/publication-ethics 


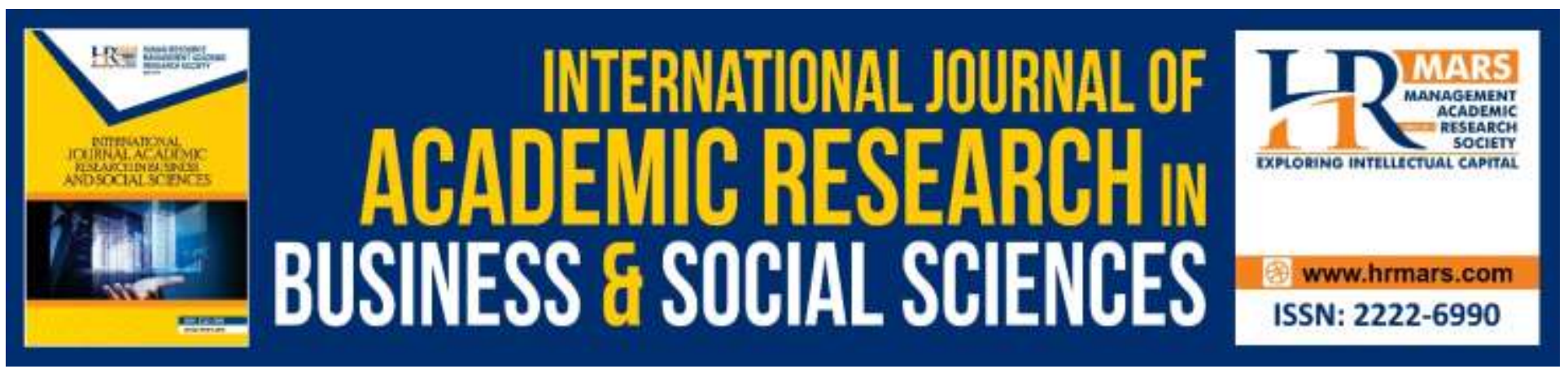

\title{
Multidimensional Psychometric Evaluation of Secondary School Student Aggression and Its Proposed Solution Based on Integrated Social Pedagogy
}

\author{
Abd. Rahim Mohd. Shariff' ${ }^{1}$, Norliza Abdul Majid², Hazuan Mohd \\ Hizan ${ }^{1}$, Ali Md Nadzalan' \& Nik Mohd. Zaki² \\ ${ }^{1}$ Faculty of Sports Science and Coaching, Sultan Idris Education University, Malaysia \\ ${ }^{2}$ Faculty of Education and Human Development, Sultan Idris Education University, Malaysia
}

\begin{abstract}
This study introduced new multidimension scale of SKiPS (student aggression score) to measure the self-aggression that were reported at secondary school in Malaysia. This scale has been developed with special focus in school by using samples from three lower secondary school (initial study: $\mathrm{N}=$ 120; main study: $N=212$ and test-retest validity: $N=40$ ) for samples from one secondary school ( $N$ $=40$ ) representing secondary school in Malaysia. Exploration analysis using the main components of analysis (PCA) reveals four factors structure; oral aggression, physical aggression and authority aggression are interrelated. Structure model assessment (SEM-PLS) showed that scaled items form four factors that relate to higher aggression factors. Structures are stable over different age groups. The scale shows sufficient internal consistency, simultaneous validity and retest stability. The implication of the study stressed the need for emotional literacy education and social competence to be applied directly in the curriculum of the Physical Education subject to enhance JERI's objectives.

Keywords: Psychometric Evaluation, Student Aggression.
\end{abstract}

\section{Introduction}

Aggressiveness during childhood can lead to aggressive and maladaptive behaviour during adolescence and subsequently to adulthood (Flannery, Vazsonyi, \& Waldman, 2007; Huessmann, 1994). This is despite the fact that aggression is a relatively stable feature (Huesmann, Eron, Lefkowitz, \& Walder, 1984). The longer the aggressive behavior continues, the more difficult to change it (Connor, 2002). Therefore, prevention of aggressive behavior should be started from the childhood. Aggressive behavior can impose negative effects in both short and long term. Aggressive children and adolescents along with their victims will experience syndrome of anxiety, depression, 
low achievement in academic performance and low self-esteem (Flannery et al., 2007; Huesmann, 1994).

The school system has the opportunity to identify and at the same time intervene the aggressiveness among the children and adolescents. In dealing with aggression among children and adolescents at school, the questionnaire, (Buss, \& Perry, 1992), on aggression that is the mostly used in Malaysia, is not suitable for school children. Several previous studies have shown that aggressive instruments that are often used (e.g. AQ) or at least some items in them are biased (Vigil-Colet, Lorenzo-Seva, Codorniu-Raga, \& Morales, 2005). Thus, the researchers decide to design the scale by themselves. Research instruments are more focused on the environment of primary and lower secondary schools.

These symptoms of misconduct are actually stemmed from many factors that are interrelated to each other. This may be due to the teen's own self, family, peers, institutions, mass media and the wider environment. Increasing rates of crime and social problems, especially among school students, are not only a concern for parents who have school children, but also have an impact on school credibility as a social control agency that should play a role in shaping the moral and behaviour of the younger generation. Variety of interpretations or labels can be given to the teenagers who prone to misconduct behaviour. For teenagers who break the norms of this local community, they will be known as having aggressive behaviours and if these teenagers are those who are still in school or underage, they are known as delinquent. In general, aggressiveness or delinquent behaviour is a violation of the rules or behaviour that is unacceptable to society.

\section{Objectives}

The purpose of this study is to identify the level of social pedagogical literacy level that the students find their impact on the type of aggression in school. To be more specific, the main objectives of this study are as follows:

a. Understanding the social pedagogy mechanism, emotional literacy and its relationship as a predictor of aggressive behaviour among students,

b. Propose social pedagogical model and emotional literacy for changing behavioural aggression among school students.

\section{Methodology}

The aggression questionnaire that has been developed is a valid, reliable and objective instrument to measure various types of student aggression in school. The goal is to develop new instrument that was built specifically and tailored to be used in school. The construction of item was based on detailed of various previous survey studies that explain about aggressiveness in school. The purpose is to include as many types of aggression (verbal, indirect, physical, suspicion, immediate aggression, anger, hostility, negativism) and direct them towards different objects in the school environment (classmates, teachers, self, objects, parents). This empirical plan contains 90 defined items to compile the first version of the student's aggressiveness questionnaire (SKiPS). All items are self-assessment, which means that students report on their own aggressiveness. Then the first step is to determine 
INTERNATIONAL JOURNAL OF ACADEMIC RESEARCH IN BUSINESS AND SOCIAL SCIENCES Vol. 9, No. 2, Feb, 2019, E-ISSN: 2222-6990 ㄷ 2019 HRMARS

the characteristics of the instrument metrics which is newly developed to be used in schools by identifying the correlation coefficient of aggression.

To achieve the objective of the pilot test, this study was conducted in two parts; first the initial study among the simple sample and the second being the main study which involved the representative samples for the whole population. The sample selection was performed by using probability sampling method which can guarantee high external validity as it gives equal opportunity to each respondent of the population to be selected as a sample of the study (Ghazali \& Sufean, 2016). Based on this reason, the researcher only focuses to one school from nine districts in Selangor and Negeri Sembilan for the selection of population samples. Subjects between the ages of 16 and 17 are the recommended groups because at this age, it is believed that there is a lot of change in behaviours and motivation in a student. At the age of sixteen to nineteen years old, students are already in the final stage of adolescence and are able to make realistic decisions (Ginzberg, 1996). They are also able to adapt to the school environment, having formed groups between them and surrounded by older friends (form five) and under them (form 1,2 and 3) as well as not involved in public examinations.

\section{Results}

Figure 1: Models of social pedagogy, emotional literacy, and social competence for change of aggressive behaviours among school students

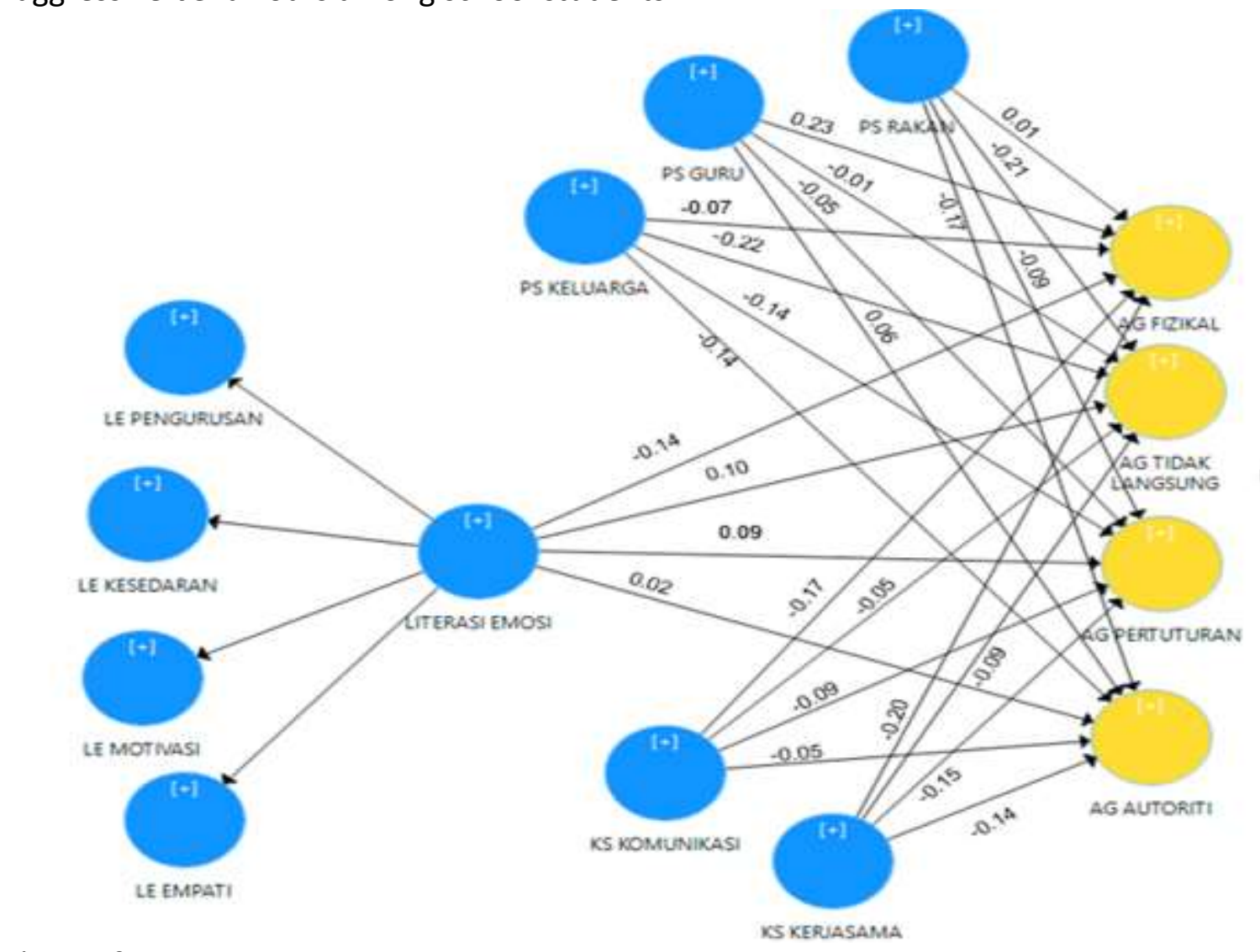

* list of terms :

Emotional Literacy (Literasi Emosi)

Social Competency (Kompetensi Sosial) 
INTERNATIONAL JOURNAL OF ACADEMIC RESEARCH IN BUSINESS AND SOCIAL SCIENCES

Vol. 9, No. 2, Feb, 2019, E-ISSN: 2222-6990 ㄷ 2019 HRMARS

emotional literacy - management (LE Pengurusan)

Komunikasi)

emotional literacy - awareness(LE Kesedaran)

kerjasama)

emotional literacy - motivation (LE Motivasi)

emotional literacy - empathy (LE Empati)

\section{Aggression}

Physical aggression (AG Fizikal)

Indirect aggression (AG Tidak Langsung)

Verbal aggression (AG Pertuturan)

Authority aggression (AG Autoriti) social competency - communication (KS

social competency - Cooperation (KS

\section{Social Pedagogy (Pedagogi Sosial)}

social pedagogy - family (PS keluarga)

social pedagogy - teachers (PS Guru)

social pedagogy - friends (PS Rakan)

Figure 1 illustrates social pedagogy, emotional literacy and social competence models for changes of aggressive behaviours among school students, as specified in SmartPLS 3. The aim of this model is to explain the influence of social pedagogy, emotional literacy, and social competence on the students' aggressive behaviours. Due to this, in this model, social pedagogy, emotional literacy, and social competency are the exogenous constructs that are combined to predict the change that occurs in the four constructs of student behaviour, which is an endogenous construct.

The construction and evaluation of the model through the SEM-PLS approach involves two stages, namely the assessment of measurement model and structure model. The assessment of measurement model is aimed to ensure the measurement modes for each construct, namely social pedagogy, emotional literacy, social competence, and student aggressiveness meet the good characteristics of psychometric measurement, in terms of reliability and validity. In the process of measurement model assessment, some items were dropped because they were empirically found not to contribute to the construct measurement that was represented. After all the construct measurement models achieve good level of validity and reliability, further analysis was conducted to the assessment of structure model. At this stage, the predictive capability by the combination of three predictive constructs; social pedagogy, emotional literacy, and social competence, on the change of behavioural aggression can be identified.

\section{Measurement Model Assessment}

Assessment of the model began with the assessment of the measurement model. Measurement model was assessed based on reliability criteria (measurement consistency), convergence validity, and discriminant validity (Hair et al., 2014). Since the measurement model for the construct of social pedagogy, emotional literacy, social competence, and student aggressiveness in this study was defined in reflective form, basically, load factor value, composite reliability, and Average Variance Extracted (AVE) were an important indicator for reliability verification and the validity of the constructs involved.

In terms of the reliability of the measurement model, generally, the value of 0.70 to 0.90 was considered to be having good reliability (Hair et al., 2014). However, since this study is an exploratory study on the relationship between social pedagogy, emotional literacy, social competence, and student aggressiveness, the target value for composite reliability was set at 0.60 (Bagozzi \& Yi, 2011; Nunnally \& Bernstein, 1994). Convergence validity assessments for the measurement model was also 
carried out at item and construct level. The factor load of each item is an important indicator for the assessment at item level, as well as the value of AVE which is an indicator for the assessment at construct level. An item needs to be maintained in construct measurement if it has a significant factor load and exceeds 0.70 . Factor load item of more than 0.70 indicates that the constructs represented able to present more than $50 \%$ variance in the item (Hair et al., 2014), indicating that the item has a good level of item reliability to measure the constructs. However, Hair et al. (2014) argued that item removal needs to be done carefully and should take into account its effect on the composite reliability and content validity of constructs that were represented. This opinion is parallel to Hulland (1999) which argued that low factor load item is often found in social science studies.

Therefore, in this study, items with high factor load (above 0.70 ) have been maintained in the construct measurement, while items with factor load too low (less than 0.40) have been dropped (Hair, Ringle, \& Sarstedt, 2011). Items with low-to-medium factor load (between 0.40 and 0.70) were dropped only if the removal increased composite reliability, while not influencing the content validity of the represented constructs (Hair et al., 2014). On the other hand, convergence validity at the construct stage is based on the AVE, which is the overall mean value of the squares load factor of the items that measuring the construct. Normally, a construct should be able to represent at least $50 \%$ variance in a set of items that measure it (Barclay, Thompson \& Higgins, 1995; Hair et al., 2014; Urbach \& Ahlemann, 2010).

Once the convergence reliability and validity of the measurement model have been proven, the final step is to prove the validity of the discriminant. Discriminant validity illustrates the extent to which a construct is completely different from the other constructs. Thus, the discrimination validity of the measurement model shows that every construct in the research model is unique and measures different things from one another (Hair et al., 2014). Proof of discrimination in this study is based on the Heterotrait-Monotrait (HTMT) ratio. HTMT is the average of the heterotrait-hetero correlation method (correlation between indicators measuring different constructs) divided by the average for the monotrait-heteromethod correlation (the correlation between the indicators measuring the same constructs). Construct is assumed to be unique when the value of HTMT between construct does not exceed 0.90 (Henseler, Ringle \& Sarstedt, 2014).

Table 1 showed the findings of the measurement model assessment based on the reliability and validity of convergence, while Table 2 showed the findings of the measurement model assessment based on discriminant validity criteria. Based on Table 1, it is found that the construct of Emotional Literacy, Physical Aggression, and Speech Aggression has met the good convergent validity criteria for measurement, i.e. by listing AVE values above 0.50. Despite of that, other constructs recorded AVE values lower than 0.50. However, despite the low AVE values, it is also found that the constructs had good measurement consistency, based on composite reliability index which exceeded 0.80. In addition, with reference to Table 2, the following, showing the findings of the HTMT ratio for the measurement of each construct, it is found that all the constructs involved in this research model have good discriminant validity. Accordingly, the researcher decided to retain all the constructs in the research model. 
INTERNATIONAL JOURNAL OF ACADEMIC RESEARCH IN BUSINESS AND SOCIAL SCIENCES Vol. 9, No. 2, Feb, 2019, E-ISSN: 2222-6990 ㄷ 2019 HRMARS

Table 1: Findings of convergence validity and internal consistency assessment of construction constructs

\begin{tabular}{|c|c|c|c|c|}
\hline \multirow[b]{2}{*}{ Constructs } & \multirow[b]{2}{*}{ Item } & \multicolumn{2}{|c|}{ Convergent validity } & \multirow{2}{*}{$\begin{array}{c}\text { Convergent consistency } \\
\text { Composite realibility } \\
>0.60\end{array}$} \\
\hline & & $\begin{array}{l}\text { Load factor } \\
>0.40\end{array}$ & $\begin{array}{l}\text { AVE } \\
>0.50\end{array}$ & \\
\hline Cooperation social competency & & $0.48-0.76$ & 0.41 & 0.87 \\
\hline Communication social competency & & $0.40-0.79$ & 0.42 & 0.92 \\
\hline Emotional literacy & & $0.76-0.86$ & 0.61 & 0.86 \\
\hline Teacher social pedagogy & & $0.40-0.65$ & 0.28 & 0.85 \\
\hline Family social pedagogy & & $0.41-0.75$ & 0.34 & 0.82 \\
\hline Friend social pedagogy & & $0.42-0.69$ & 0.29 & 0.84 \\
\hline Authority aggression & & $0.60-0.79$ & 0.47 & 0.84 \\
\hline Physical aggression & & $0.58-0.78$ & 0.50 & 0.85 \\
\hline Speech aggression & & $0.61-0.79$ & 0.51 & 0.86 \\
\hline Indirect aggression & & $0.56-0.79$ & 0.46 & 0.81 \\
\hline
\end{tabular}

Table 2: Assessment of discrimination validity estimates for construct measurement

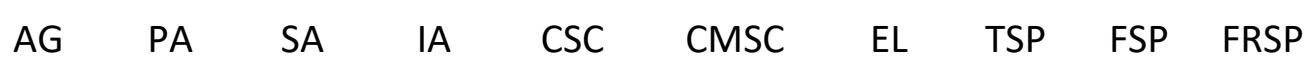

\begin{tabular}{|c|c|c|c|c|c|c|c|c|c|}
\hline \multicolumn{10}{|l|}{$\mathrm{AA}$} \\
\hline PA & 0.74 & & & & & & & & \\
\hline SA & 0.60 & 0.58 & & & & & & & \\
\hline IA & 0.76 & 0.55 & 0.68 & & & & & & \\
\hline CSC & 0.26 & 0.33 & 0.21 & 0.22 & & & & & \\
\hline CMSC & 0.21 & 0.32 & 0.19 & 0.26 & 0.27 & & & & \\
\hline EL & 0.29 & 0.33 & 0.24 & 0.32 & 0.55 & 0.28 & & & \\
\hline TSP & 0.22 & 0.32 & 0.15 & 0.26 & 0.24 & 0.28 & 0.41 & & \\
\hline FSP & 0.37 & 0.37 & 0.28 & 0.50 & 0.31 & 0.38 & 0.41 & 0.54 & \\
\hline FRSP & 0.35 & 0.27 & 0.23 & 0.40 & 0.44 & 0.38 & 0.52 & 0.52 & 0.64 \\
\hline
\end{tabular}

\section{Structural Model Assessment}

After the measurement model in this study is proven to have good validity and reliability, the analysis is continued on the assessment of the structure model. The structure model in this study is assessed in terms of predicting capability by a combination of social pedagogy, emotional literacy, and social competence on student aggressiveness. The model predicting capability is based on the determinant coefficient value, $R^{2}$ and the Stone-Geisser coefficient, $Q^{2}$.

The determinant coefficient, $R^{2}$, measures the prediction accuracy of the structure model and is calculated as a square for the correlation between the true value and the predicting value of an 
INTERNATIONAL JOURNAL OF ACADEMIC RESEARCH IN BUSINESS AND SOCIAL SCIENCES Vol. 9, No. 2, Feb, 2019, E-ISSN: 2222-6990 ㄷ 2019 HRMARS

endogenous construct. $R^{2}$ values are between 0 and 1, with greater values showing higher accuracy prediction. The target value for $R^{2}$ depends on the area of study and the complexity of the model being built. However, in general, the $R^{2}$ thresholds of $0.25,0.50$, and 0.75 are considered weak, medium, and strong (Henseler, Ringle, \& Sinkovics, 2009; Hair et al., 2014). In addition to accuracy, another aspect of the prediction being evaluated is relevancy or suitability. More specifically, the structure model that has prediction relevancy is able to accurately predict an indicator data that measures endogenous constructs (Hair et al., 2014). The relevance of prediction in the structure model is evaluated by based on the value of Stone-Geisser coefficient, $Q^{2} . Q^{2}$ values need to be positive to prove that prediction models are relevant or appropriate.

The model predicting capabilities are shown in Table 3 . The positive $Q^{2}$ values as in Table 3 showed that the change in student aggression is relevant predicted by social pedagogy constructs, emotional literacy, and social competence. However, in terms of accuracy prediction, the $R^{2}$ value suggests that the combination of the three predictor constructs has a poorly predicted accuracy over the student's aggression change. The greatest contribution is given by social pedagogy, emotional literacy, and social competence over a change of physical aggression, which is $22 \%$.

Table 3: Value that demonstrate model predicting capability.

\begin{tabular}{lll}
\hline Target construct & $R^{2}$ & $Q^{2}$ \\
\hline Authority aggression & 0.13 & 0.05 \\
Physical aggression & 0.22 & 0.10 \\
Speech aggression & 0.09 & 0.03 \\
Indirect aggression & 0.18 & 0.06 \\
\hline
\end{tabular}

Further research on the strength and significance of the relationship between each predictive constructor with physical aggression is shown in Table 4 below. There are six relationships formed between the predictive constructs and the physical aggression constructs, as specified in this model of the study. However, out of the six relationships, two of them were found to be insignificant, i.e. between family social pedagogy and friend social pedagogy, with physical aggression. It is also found that the relationship between social competence of cooperation, social communication competence, and emotional literacy with physical aggression is negative. On the other hand, a positive relationship is formed between the teacher's social pedagogy with the student's physical aggression.

Table 4: strength and significant of relationship between predictive construct and physical aggression

\begin{tabular}{lcccc}
\hline & $\begin{array}{c}\text { Coefficient } \\
\text { pathway, } 6\end{array}$ & $\begin{array}{c}\text { Standard } \\
\text { deviation }\end{array}$ & t-value & $\begin{array}{c}p- \\
\text { value }\end{array}$ \\
\hline Cooperation social competency $\rightarrow$ Physical aggression & -0.20 & 0.07 & 2.73 & 0.00 \\
\hline $\begin{array}{l}\text { Communication social competency } \rightarrow \text { Physical } \\
\text { aggression }\end{array}$ & -0.17 & 0.06 & 2.73 & 0.00 \\
\hline Emotional literacy $\rightarrow$ Physical aggression & -0.10 & 0.07 & 1.37 & 0.09 \\
\hline Teacher social pedagogy $\rightarrow$ Physical aggression & 0.23 & 0.08 & 3.05 & 0.00 \\
\hline Family social pedagogy $\rightarrow$ Physical aggression & -0.07 & 0.08 & 0.91 & 0.18 \\
\hline Friend social pedagogy $\rightarrow$ physical aggression & 0.01 & 0.07 & 0.18 & 0.43 \\
\hline
\end{tabular}




\section{Conclusion}

This study presents the first step in developing new instrument with the aim of identifying aggressive students at school as the step towards preventing their aggressive behaviour in the future. Studies have developed psychometrically valid instruments specifically designed to measure aggression in school settings. Previous research in aggression using the AQ (Aggression Questionnaire) developed by Buss and Perry, (1992). However, the driving force in developing this instrument is to show sensitivity to cultural and language differences. SKiPS Questionnaire is believed to be able to distinguish effectively among students with varying degrees of aggressiveness. The instrument of this study has only run through the first stage in the development of the instrument and before further use, the instrument shall be tested on other samples for validity and reliability. The use of SKiPS to gain aggression correlation level in schools should be understood as a guide for the possibility of further investigation. The results showed that there is an important relationship of aggression and the use of leisure, attitudes towards school, and educational aspirations. Therefore, further research needs to be done in this direction by analyzing this relationship in more detail. Not only does the study show important relationships at the student level but also at the teacher level. Given that these are just a few factors that influence student aggression, there are still many more that cannot be identified. The importance of this study is to show that the use of aggressive questionnaires along with other factors provides a possible approach to deal with the aggression among young children and developing approaches to reduce the level of student aggression.

\section{Acknowledgement}

This research is supported by Universiti Pendidikan Sultan Idris under University Research Grant (2017-0120-106-01).

\section{References}

Bagozzi, R. P., \& Yi, Y. (2011). Specification, evaluation, and interpretation of structural equation models. Journal of the Academy of Marketing Science, 40(1), 8-34

Barclay, D., Higgins, C., \& Thompson, R. (1995). The partial least squares approach to causal modeling: Personal computer adoption and use as an illustration. Technology Studies, 2, 285-323

Buss, A. H., Perry, M. (1992). The aggression questionnaire. Journal of Personality and Social Psychology, 63 (3), 452-459.

Connor, D. F. (2002). Aggression and antisocial behaviour in children and adolescents. reserach and treatment. New York, USA: Guilford press.

Flannery, D. J., Vazsonyi A.T., \& Waldman, I. D. (2007). The Cambridge handbook of violent behaviour and aggression. Cambridge: Cambridge University Press.

Ghazali, D. S., \& Sufean, H. (2016). Metodologi penyelidikan dalam pendidikan: amalan dan analisis kajian. Kuala Lumpur : Penerbit Universiti Malaya

Ginzberg, E. (1996). Toward a theory of occupational choice. Occupations, 30, 491-494.

Hair, J. F., Ringle, C. M., \& Sarstedt, M. (2011). PLS-SEM: Indeed a Silver Bullet. The Journal of Marketing Theory and Practice, 19(2), 139-152

Hair, J. F., Hult, G. M., Ringle, C. M., \& Sarstedt, M. (2014). A primer on partial least squares structural equations modeling (PLS-SEM). Los Angeles: SAGE.

Henseler, J., Ringle, C. M., \& Sinkovics, R. R. (2009). The use of Partial Least Squares path modeling in 
INTERNATIONAL JOURNAL OF ACADEMIC RESEARCH IN BUSINESS AND SOCIAL SCIENCES

Vol. 9, No. 2, Feb, 2019, E-ISSN: 2222-6990 C 2019 HRMARS

international marketing. Advances in International Marketing, 20, 277-319

Henseler, J., Ringle, C. M., \& Sarstedt, M. (2015). A new criterion for assessing discriminant validity in variance-based structural equation modeling. Journal of the Academy of Marketing Science, 43(1), 115-135.

Huesmann, L. R. (1994). Aggressive behaviour - current perspectives. Plenum Press: New York and London.

Huesmann, L. R., Eron, L. D., Lefkowitz, M. M., \& Walder, L. O. (1984). Stability of aggression over time and generations. Developmental Psychology, 20, 1120-1134.

Hulland, J. (1999). Use of partial least squares (PLS) in strategic management research: a review of four recent studies. Strategic Management Journal, 20(2), 195-204.

Nunnally, J. C., \& Bernstein, I. H. (1994). Psychometric theory. United States of America: McGraw-Hill.

Nunnally, J. C., \& Bernstein, I. H. (1994). Psychometric theory (edisi ke tiga). New York, NY: McGrawHill.

Urbach, N., \& Ahlemann, F. (2010). Structural equation modeling in information systems research using partial least squares. Journal of Information Technology Theory and Application, 11(2), 5-40.

Vigil-Colet, A., Lorenzo-Seva, U., Codorniu-Raga, M. J., \& Morales, F. (2005). Factor structure of the aggression questionnaire among different samples and languages. Aggressive Behaviour, 31, 601-608. 